\title{
EFFECT OF RING IN IMINES AND ENAMINES TAUTOMERISM IN GAS PHASE AND SOLUTION: A COMPUTATIONAL STUDY
}

\author{
AZIN MOHAMADI ${ }^{1}$, MEISAM SHABANIAN ${ }^{2 *}$, MOHSEN HAJIBEYGI ${ }^{3}$ HASSAN MOGHANIAN ${ }^{4}$, \\ ${ }^{'}$ Young Researchers Club, Arak Branch, Islamic Azad University, Arak, Iran \\ ${ }^{2}$ Department of Chemistry, Farahan Branch, Islamic Azad University, Farahan, Iran \\ ${ }^{3}$ Department of Chemistry, Varamin Pishva Branch, Islamic Azad University, Varamin Pishva, Iran \\ ${ }^{4}$ Department of Chemistry, Dezful Branch, Islamic Azad University, Dezful, Iran
}

(Received: December 6, 2011 - Accepted: November 21, 2012)

\begin{abstract}
Tautomeric structures from imine-enamine equilibria with rings of different size were geometrically optimized at the B3LYP/6-311++G** level of theory. Then important molecular parameters, IR frequencies, NBO and dipole moment results in the gas phase and solution were extracted. The energetic results show that relative stability of enamine tautomer (versus imine tautomer) increases with the increase of ring size and polarity of solvent. Calculated frequencies show the effect on the $\mathrm{C}=\mathrm{N}$ frequency (imine tautomer) is attributed to ring size. The effect of increasing ring stain by decreasing ring size is to increase the $\mathrm{C}=\mathrm{N}$ frequency. In addition, variation of dipole moments and NBO charges on atoms in the solvents are studied.
\end{abstract}

Keyword: DFT study, NBO analysis, PC model, imine, enamine

\section{INTRODUCTION}

The imines formation is a particularly important chemical reaction in some biological processes $[1,2]$. For example, the covalent binding of carbonylcontaining compounds to an enzyme usually involves the formation of imine. The imine moiety is formed by condensation of carbonyl groups of ketone or aldehyde with a primary or secondary amine. Equilibrium between imine and enamine may take place when at least one hydrogen atom is bonded with the imine nitrogen. The mole fractions of these species depend on the symmetry of the parent ketone and the substituents on the amine [3].

Since the imines bonds are labile and readily hydrolyzed to the corresponding ketones, it is difficult accurately to monitor and determine which factors influents the extent of imines formations. For example, experiments using Raman and infrared spectroscopy to study the stretching frequencies of imines have been reported. By studying the kinetics of imine formation from acetophenone and substituted aniline, Lee et al. were successful in monitoring the conversion from ketones to imines [4].

Tautomeric conversions [5-7] have been mostly investigated by many chemists during last decades. Recently, the study of tautomerism received renewed attention due to its importance on determination of compounds' properties and their area of applications.

In recent years, the understanding of the tautomerism progresses due to the investigation of this phenomenon became one of the major topics in theoretical chemistry. For example, tautomerism in keto-enol [8,9], imineenamine [10,11], purines [12], pirimidines [13] and many other systems [14-15] have been studied during past two decades. Thereupon, compounds containing tautomers can be the subject of interest for the theoreticians. In title compounds, the tautomerism affects their chemical and biological activities, and any systematic publications on theoretical study of their tautomerisms have been not take place. In this connection, it seems to be important to study the complete scheme of tautomerism and the reaction pathways between different tautomers. In this line, effects of solvent on this tautomerism should also be worked out clearly [16].

In this article, molecular parameters, relative energies, NBO analysis, dipole moments and vibrational frequencies of imines and enamines with different rings have been calculated using B3LYP/6-311++ $\mathrm{G}^{* *}$ level of theory. Furthermore, the effects of solvent have been investigated using benzene (non polar), acetone (aprotic) and water (protic) as solvents.

\section{Computational Methods}

All calculations were carried out on a Pentium personal computer by means of GAUSSIAN03 program package [17]. First, the structures of the compounds were drawn using Gauss View 03 [18]. To characterize the optimized geometries, the vibrational frequencies for all conformers have been calculated at B3LYP levels. The stationary structures, corresponding to the minimum of potential energy surface, were confirmed by ascertaining the fact that all ground states have only positive real frequencies. The tautomers were also optimized in solvents according to the polarizable continuum method of Tomasi and co-workers, which exploits the generating polyhedra procedure [19-22] to build the cavity in the polarizable continuum medium, where the solute is accommodated. Atomic charges in all the structures were obtained using the Natural Population Analysis (NPA) method within the Natural Bond Orbital (NBO) approach [23].

\section{RESULTS AND DISCUSSION}

\section{Optimized parameters}

In this paper, energies, molecular properties and tautomeric interconversion in imine and enamine with 3-membered ring (R3I, R3E), 4-membered ring (R4I, R4E), 5-membered ring (R5I, R5E) and 6-membered ring (R6I, R6E) have been studied. The structures, names and numbering schemes of selected compounds are presented in Fig. 1. The selected molecules can be presented by two tautomers, imine (I) and enamine (E). Only the most stable conformer of each structure has been considered in this study. The tautomerism in the selected structures is similar to 1,3-sigmatropic rearrangement. This subject attracts considerable attention of scientists, especially in cyclic system [24, 25]. The results of energy comparisons of the tautomers in the gas phase and different solvents are given in Table 1. In the gas phase imine form is more stable than the other form however with increase of the size of ring difference between the tautomers obviously decreases. The major difference between them in a gas phase for 3-membered ring was found to be $-15.522 \mathrm{kcal} \mathrm{mol}^{-1}$.

The optimized parameters of all structures are listed in Table 2. The N1-C2 bond length, reported in the first row of table, lies in the range of 1.356-1.396 $\AA$ in E tautomers and 1.254-1.273 $\AA$ in I tautomers. In E tautomers, the N1-C2 bond length increases with the increase of ring size, because of decreasing in ring strain. The $\mathrm{C} 2-\mathrm{C} 3$ bond length lies in the range of 1.301-1.346 $\AA$ in $\mathrm{E}$ tautomers and 1.458-1.521 $\AA$ in I tautomers. Next three rows in Table 2 consist of N1-H4, C3-H4 and $\mathrm{C} 2-\mathrm{H} 5$ bond lengths. All of these bond lengths have expected quantities between 1.019 and $1.098 \AA$ in tautomers. The rows 6 and 7 in Table 2 consist of bond angles. The variation of $\mathrm{N} 1-\mathrm{C} 2-\mathrm{C} 3$ endocyclic angle strictly depends on the ring size. For example, its value changes from 152.5 deg in R3E to 124.2 deg in R6E. Moreover, because of decreasing in ring's strain, $\mathrm{C} 2-\mathrm{C} 3-\mathrm{H} 5$ bond angle decreases by the increase of ring size. 
Table 1. Total energies ${ }^{\mathrm{a}}$ at $\mathrm{B} 3 \mathrm{LYP} / 6-311++\mathrm{G}^{* *}$ and relative energy $\mathrm{b}^{\mathrm{b}}$ in the gas phase and in the solvents.

\begin{tabular}{|c|c|c|c|c|}
\hline Tautomer & Gas (1.0) & Benzene (2.2) & Acetone (21.0) & Water (78.4) \\
\hline R3E $\mathrm{E}^{\mathrm{a}}$ & -211.3525873 & -211.3568241 & -211.3603664 & -211.3607448 \\
\hline $\mathrm{R}^{2} \mathrm{I}^{\mathrm{a}}$ & -211.3773237 & -211.3808351 & -211.3838926 & -211.3842102 \\
\hline E2-E1 ${ }^{b}$ & -15.522 & -15.067 & -14.763 & -14.725 \\
\hline R4E $\mathrm{E}^{\mathrm{a}}$ & -250.7172679 & -250.7211039 & -250.7243238 & -250.72475 \\
\hline $\mathrm{R} 4 \mathrm{I}^{\mathrm{a}}$ & -250.7262722 & -250.7296334 & -250.7325697 & -250.7329463 \\
\hline E2-E1 ${ }^{b}$ & -5.650 & -5.352 & -5.174 & -5.143 \\
\hline $\mathrm{R}^{2} \mathrm{E}^{\mathrm{a}}$ & -290.0770985 & -290.080849 & -290.0840065 & -290.0842934 \\
\hline $\mathrm{R}^{2} \mathrm{I}^{\mathrm{a}}$ & -290.0803287 & -290.0837213 & -290.0866905 & -290.0870793 \\
\hline E2-E1 ${ }^{b}$ & -2.027 & -1.802 & -1.684 & -1.748 \\
\hline R6E & -329.406644 & -329.4101458 & -329.413081 & -329.4135393 \\
\hline $\mathrm{R}^{2} \mathrm{I}^{\mathrm{a}}$ & -329.4080787 & -329.4113035 & -329.414144 & -329.4145599 \\
\hline E2-E1 ${ }^{b}$ & -0.900 & -0.726 & -0.667 & -0.640 \\
\hline
\end{tabular}

${ }^{\mathrm{a}}$ Hartree

${ }^{\mathrm{b}}$ Relative energy in $\mathrm{kcal} \mathrm{mol}^{-1}$.

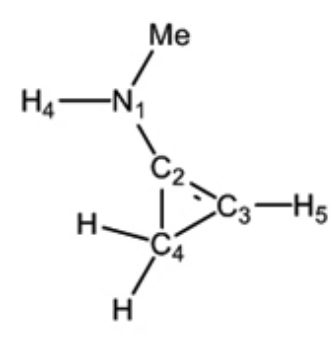

R3E<smiles>CN=C1CC(C)C1(C)C</smiles>

R4I<smiles>CN=C1[C@H](C)N1C</smiles>

R3I<smiles>CC1=C(N(C)C)CCC1C</smiles>

R5E<smiles>CC1=C(N(C)C)CC1C</smiles>

R4E

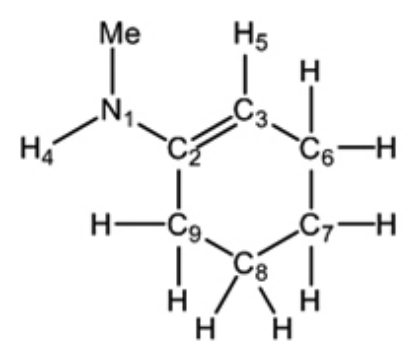

R6E<smiles>[2H][C@H]1C(C)(C)C(=NC)[C@H](C)C1([2H])[2H]</smiles>

R6I

Figure 1. Tautomeric forms of imine and enamine and numbering of imine and enamine rings. 
Table 2. Selected molecular parameters of optimized structures at B3LYP level of theory ${ }^{\mathrm{a}}$

\begin{tabular}{|c|c|c|c|c|c|c|c|c|}
\hline Parameter & R3E & R3I & R4E & R4I & R5E & R5I & R6E & R6I \\
\hline N1-C2 & 1.356 & 1.254 & 1.373 & 1.258 & 1.383 & 1.266 & 1.396 & 1.273 \\
\hline C2-C3 & 1.301 & 1.458 & 1.351 & 1.521 & 1.346 & 1.534 & 1.346 & 1.521 \\
\hline N1-H4 & 1.010 & - & 1.009 & - & 1.008 & - & 1.009 & - \\
\hline C3-H4 & - & 1.085 & - & 1.092 & - & 1.096 & - & 1.098 \\
\hline C3-H5 & 1.07 & 1.085 & 1.082 & 1.093 & 1.082 & 1.092 & 1.084 & 1.089 \\
\hline N1-C2-C3 & 152.517 & 145.671 & 135.847 & 130.400 & 128.877 & 129.735 & 124.272 & 128.665 \\
\hline C2-C3-H5 & 151.480 & 118.839 & 134.095 & 113.958 & 125.393 & 112.403 & 119.785 & 107.649 \\
\hline
\end{tabular}

${ }^{a}$ All bond length have been reported in $\AA$ and angles in deg.

The calculated dipole moments for the tautomers are presented in Table 3. In a gas phase the dipole moment decreases with the increase of ring size in E forms but in the imine forms we can see an exception in 5-membered ring tautomer.

Table 3. Calculated dipole moments of optimized tautomers (Debye)

\begin{tabular}{|c|c|c|c|c|}
\hline Tautomer & Gas (1.0) & Benzene (2.2) & Acetone (21.0) & Water (78.4) \\
\hline R3E & 2.0887 & 2.4143 & 2.7349 & 2.7701 \\
\hline R3I & 1.9250 & 2.3395 & 2.7473 & 2.7960 \\
\hline R4E & 1.6606 & 1.9723 & 2.2928 & 2.3294 \\
\hline R4I & 1.9657 & 2.3959 & 2.8199 & 2.8763 \\
\hline R5E & 1.4657 & 1.7777 & 2.1011 & 3.1188 \\
\hline R5I & 2.0409 & 2.4913 & 2.9441 & 1.7336 \\
\hline R6E & 1.1581 & 1.4251 & 1.6955 & 3.0434 \\
\hline R6I & 2.0220 & 2.4977 & 2.9761 & \\
\hline
\end{tabular}

Enamine forms have higher dipole moment than the imine forms with 3-membered ring in gas phase and in benzene, and this exception can be caused with the high ring strain.

Table 4 shows NBO charges have been calculated by means of the Natural Population Analysis (NPA) for optimized structures of imine-enamine tautomers in the gas phase and solvents. Each tautomer shows $\mathrm{N}$ atom bearing the largest negative net charge. The last $\mathrm{C}$ atoms in enamine and imine and $\mathrm{N}$ atom will most effectively interact with electrophiles.

Table 4. Calculated NBO charges on ring atoms and $\mathrm{N}$ atom.

\begin{tabular}{|c|c|c|c|c|c|c|c|c|}
\hline & Atom & N1 & $\mathrm{C} 2$ & $\mathrm{C} 3$ & $\mathrm{C} 4$ & $\mathrm{C} 5$ & C6 & $\mathrm{C} 7$ \\
\hline \multicolumn{9}{|l|}{$\varepsilon=$} \\
\hline 1.0 gas & & -0.623 & 0.196 & -0.298 & -0.398 & - & - & - \\
\hline 2.2 benz & & -0.632 & 0.199 & -0.318 & -0.405 & - & - & - \\
\hline 21.0 acet & R3E & -0.639 & 0.202 & -0.336 & -0.410 & - & - & - \\
\hline 78.4 wat & & -0.640 & 0.202 & -0.338 & -0.411 & - & - & - \\
\hline 1.0 & & -0.434 & 0.278 & -0.431 & -0.465 & - & - & - \\
\hline 2.2 & & -0.462 & 0.283 & -0.437 & -0.466 & - & - & - \\
\hline 21.0 & R3I & -0.487 & 0.288 & -0.442 & -0.466 & - & - & - \\
\hline 78.4 & & -0.490 & 0.289 & -0.442 & -0.466 & - & - & - \\
\hline 1.0 & & -0.631 & 0.182 & -0.313 & -0.374 & -0.391 & - & - \\
\hline 2.2 & & -0.641 & 0.184 & -0.329 & -0.378 & -0.394 & - & - \\
\hline 21.0 & $\mathrm{R} 4 \mathrm{E}$ & -0.650 & 0.186 & -0.344 & -0.381 & -0.396 & - & - \\
\hline 78.4 & & -0.651 & 0.185 & -0.346 & -0.381 & -0.396 & & \\
\hline 1.0 & & -0.464 & 0.309 & -0.430 & -0.382 & -0.464 & - & - \\
\hline 2.2 & & -0.491 & 0.316 & -0.435 & -0.383 & -0.467 & - & - \\
\hline 21.0 & R4I & -0.515 & 0.319 & -0.439 & -0.383 & -0.469 & - & - \\
\hline 78.4 & & -0.518 & 0.319 & -0.469 & -0.383 & -0.439 & - & - \\
\hline 1.0 & & -0.631 & 0.187 & -0.314 & -0.393 & -0.371 & -0.407 & - \\
\hline 2.2 & & -0.642 & 0.187 & -0.329 & -0.395 & -0.374 & -0.410 & - \\
\hline 21.0 & R5E & -0.651 & 0.188 & -0.342 & -0.397 & -0.376 & -0.412 & - \\
\hline 78.4 & & -0.652 & 0.188 & -0.343 & -0.397 & -0.376 & -0.413 & - \\
\hline 1.0 & & -0.476 & 0.311 & -0.432 & -0.383 & -0.382 & -0.466 & - \\
\hline 2.2 & & -0.502 & 0.320 & -0.436 & -0.385 & -0.383 & -0.469 & - \\
\hline 21.0 & R5I & -0.525 & 0.323 & -0.438 & -0.385 & -0.385 & -0.473 & - \\
\hline 78.4 & & -0.529 & 0.325 & -0.439 & -0.386 & -0.385 & -0.473 & - \\
\hline 1.0 & & -0.635 & 0.184 & -0.304 & -0.396 & -0.376 & -0.376 & -0.407 \\
\hline 2.2 & & -0.674 & 0.184 & -0.315 & -0.398 & -0.378 & -0.378 & -0.411 \\
\hline 21.0 & R6E & -0.657 & 0.184 & -0.325 & -0.400 & -0.380 & -0.379 & -0.414 \\
\hline 78.4 & & -0.658 & 0.183 & -0.327 & -0.400 & -0.380 & -0.380 & -0.414 \\
\hline 1.0 & & -0.475 & 0.307 & -0.422 & -0.377 & -0.383 & -0.374 & -0.450 \\
\hline 2.2 & & -0.498 & 0.310 & -0.424 & -0.378 & -0.385 & -0.375 & -0.453 \\
\hline 21.0 & R6I & -0.521 & 0.318 & -0.427 & -0.379 & -0.387 & -0.376 & -0.456 \\
\hline 78.4 & & -0.525 & 0.319 & -0.427 & -0.379 & -0.387 & -0.376 & -0.457 \\
\hline
\end{tabular}


Five important vibrational frequencies of all structures are listed in Table 5. In first row, N1-H4 frequency (this frequency only exists in tautomer E) is reported, R3E ring has higher magnitude and $\mathrm{C} 3-\mathrm{H} 4$ too. Table 5 indicates that $\mathrm{C} 2=\mathrm{N} 1$ frequencies decreases with the increase of ring size. For enamines, $\mathrm{C} 3-\mathrm{H} 5$ frequencies decrease, but not monotonically.
$\mathrm{C} 2=\mathrm{C} 3$ in $\mathrm{R} 4 \mathrm{E}$ shows lower magnitude and it corresponds to ring strain in this tautomer. The unexpected frequencies value of four ring tautomers have demonstrated that this change in rings reveals to decreasing of the ring strain.

Table 5. Selected frequencies (in $\mathrm{cm}^{-1}$ ) of tautomers at B3LYP/6-311++G** level of theory.

\begin{tabular}{|c|c|c|c|c|c|c|c|c|}
\hline Bond & R3E & R3I & R4E & R4I & R5E & R5I & R6E & R6I \\
\hline N1-H4 & 3585.91 & - & 3489.63 & - & 3498.45 & - & 3495.99 & - \\
\hline C3-H4 & - & 3190.16 & - & 3079.35 & - & 3088.14 & - & 3097 \\
\hline C2=N1 & - & 1870.16 & - & 1786.81 & - & 1742.53 & - & 1732 \\
\hline C2=C3 & 1860.52 & - & 1676.83 & - & 1681.26 & - & 1698.02 & - \\
\hline C3-H5 & 3296.83 & 3190.16 & 3168.86 & 3079.35 & 3170.97 & 3088.14 & 3150.13 & 3097 \\
\hline
\end{tabular}

The variation of frequencies versus ring size is important because they shows meaningful relation between empirical parameters (frequency) and simple theories, such as bond angle, ring's strain and hybridation.

\section{Solvent effects}

Solvent effects are relevant in tautomers stability phenomena, since polarity differences among tautomers can induce significant changes in their relative energies in solution. PCM/B3LYP calculations were used to analyze the solvent effects on tautomerism of all the tautomers. It is important to stress that the PCM model does not consider the presence of explicit solvent molecules; hence specific solute-solvent interactions are not described and the calculated solutions effects arise only from mutual solute-solvent electrostatic polarization. The data presented in Table 1 show that polar solvents increase the stability of all the tautomers in comparison with the gas phase. The difference between the total energies shows a regular decrease (except for 5-membered ring in acetone) when changing from gas phase to most polar solvents (water)

The solvent represented by a polarizable continuum shows a significant effect on the dipole moments of the individual solute conformers. The dipole moments increase from the gas phase to the solution as well as by increasing the solvent polarity. The most significant variations being obtained have been observed in R6I form with $3.0434 \mathrm{D}$ (Table 3). We have examined the charge distribution of tautomers in the solvent as well as in a gas phase by using calculated NBO charges. The charge distribution in solvents with increase of polarity differently varies for any atoms.

\section{CONCLUSIONS}

In this work, DFT calculation has been applied to study of tautomerism in imines and enamines with different rings in the gas phase and in three solvents. The following points emerge from the present study:

1. As the polarity increases, the total energy of all compounds become more negative.

2. Relative stability of enamine tautomer versus imine tautomer increases with the increase of ring size.

3. Dipole moments of all tautomers increase as the polarity of solvent increases too.

4. The charges on all the positions were affected by solvents. In addition with increase of dielectric constant a variation was found.

\section{REFERENCES}

1. Smith, S. O.; Pardeon, T. A.; Mulder, P. P. J.; Cuny, B.; Lugtenburg J.; Mathies, R. Biochemistry, , 22, 6141 (1983).

2. Vdovenko, S. I.; Gerus I. I.; Wo'jcik, J. J. Phys. Org. Chem., 14, 533 (2001).

3. Zhong, H.; Stewart, E. L.; Kontoyianni M.; Bowen, J. P. J. Chem. Theory Comput., 1, 230 (2005).

4. Lee, M.; Kim, H.; Rhee H.; Choo, J. Bull. Korean Chem. Soc., 24, 205 (2003).

5. Belova, N. V.; Oberhammer, H.; Girichev G. V.; Shlykov, S. A. J. Phys Chem. A, 112, 3209 (2008)

6. Buzykin, B. I.; Mronova, E. V.; Nabiullin, V. N.; Azancheev, N. M.; Awakumova, L. V.; Rizvanov, I. K.; Gubaiduffin, A. T.; Litvinov I. A.; Syakaev, V. V. Russ. J. Gen. Chem., 78, 461 (2008).

7. Dubonosov, A. D.; Minkin, V. I.; Bren, V. A.; Shepelenko, E. N.; Tsukanov, A. V.; Starikov A. G.; Borodkin, G. S. Tetrahedron, 64, 3160 (2008).
8. Misra A.; Dalai, S. J. Mol. Struct. THEOCHEM, 807, 33 (2007).

9. Zborowski K.; Korenova, A. J. Mol. Struct. THEOCHEM, 683, 15 (2004).

10. Oziminski, W. P.; Dobrovolski J. C.; Mazurek, A. P. J. Mol. Struct. THEOCHEM, 107, 680 (2004)

11. Dines T. J.; Onoh, H. Spectrochim. Acta A, 64, 891 (2006).

12. Shukla M. K.; Mishra, S. K. J. Comput. Chem. 21, 826 (2000).

13. Bonacin, J. A.; Melo D.; Toma, H. E. Vib. Spectrosc. 44, 133 (2007).

14. Angelova S.; Enchev, V. J. Mol. Struct. THEOCHEM., 711, 201 (2004).

15. Grochowski, J.; Serda P.; Kozik, B. J. Mol. Struct. THEOCHEM. 689, 43 (2004).

16. Tavakol, H. J. Mol. Struct. THEOCHEM., 956, 97 (2010).

17. Frisch, M. J.; Trucks, G. W.; Schlegel, H. B. et al., Gaussian 03, Revision B.03, Gaussian, Inc. Pittsburgh PA (2003).

18. Dennington, R.; Keith, T.; Millam, J.; Eppinnett, K.; Hovell W. L.; Gilliland. R.; GaussView, Version 309., Semichem, Inc, Shawnee Mission, KS (2003).

19. Miertus S.; Scrocco, E.; Tomasi J. J. Chem. Phys. 55, 117 (1981).

20. Cances, M. T.; Mennucci V.; Tomasi J. J. Chem. Phys., 107, 3032 (1997).

21. Cossi, M.; Barone, V.; Mennucci B.; Tomasi, J. Chem. Phys. Lett., 286, 253 (1998).

22. Barone, V.; Cossi M.; Tomasi, J. J. Comp. Chem., 19, 404 (1998).

23. Najafi Chermahini, A.; Nasr-Esfahani, M.; Dalirnasab, Z.; Abdol Dabbagh H.; Teimouri A. J. Mol. Struct. THEOCHEM.., 820, 7 (2007).

24. Erdem, S.; Uyar, F.; Karahan O.; Yelekc, K. J. Mol. Struct. THEOCHEM., 814, 61 (2007).

25. Tao H. R.; Fang, D. C. Theor. Chem. Acc. 121, 91 (2008). 